\title{
La filogénesis humana según la teoría mimética de René Girard
}

\section{The human phylogeny according to René Girard's mimetic theory}

AGUSTÍN MORENO FERNÁNDEZ*

\begin{abstract}
Resumen: La teoría mimética de René Girard contiene una interpretación acerca del origen de la especie humana y el proceso de hominización. Su propuesta destaca por el afán de aunar las aportaciones de la etología animal y de la antropología cultural, en torno al mimetismo y su hipótesis del mecanismo del chivo expiatorio. Nuestro objetivo es presentar una síntesis de sus consideraciones acerca de la antropogénesis, presentes a lo largo de su obra. Palabras clave: filogénesis humana, teoría mimética, René Girard, hominización, mecanismo del chivo expiatorio.
\end{abstract}

\begin{abstract}
The mimetic theory of René Girard includes one interpretation about the origin of human species and the humanization process. Girard proposes to combine the achievements of the animal ethology and cultural anthropology, around the mimetism and the scapegoat mechanism. The objective of our article is to present a synthesis of his thinking about the anthropogenesis.
\end{abstract}

Key words: human philogenesis, mimetic theory, René Girad, humanization, scapegoat mechanism.

\section{Introducción}

El objeto de este artículo es plantear la pregunta ¿qué es el hombre?, partiendo de un plano filogenético y, particularmente, a través de la teoría mimética de Girard. Para este pensador, la cuestión de la mímesis en el comportamiento humano es principal y será tenida en cuenta. Aquí incidiremos más en la cuestión del mecanismo del chivo expiatorio o, dicho de otra manera, el origen de lo humano vinculado a un proceso espontáneo de control de la violencia mediante el crimen contra víctimas que procuraría un efecto catártico y unificador a la comunidad. No obstante, nunca dejaríamos de considerar perspectivas de un mismo ciclo o proceso

Fecha de recepción: 16/05/2013. Fecha de aceptación: 25/06/2013.

* Doctor en Filosofía. Miembro del proyecto de investigación "Las pasiones y la naturaleza humana", del Dpto. de Filosofía II de la Universidad de Granada (FFI2010-16650, Ministerio de Economía y Competitividad, Plan Nacional I+D+i) y del Grupo de Investigación “Antropología y Filosofía” (SEJ-126, PAIDI, Junta de Andalucía). morenofdez@ugr.es. Dos de sus publicaciones recientes son: “Ortega y Gasset: religión y problema de España”, en: Pensamiento, vol. 67, n 253, 2011, y La evaluación de la modernidad en la teoría mimética de René Girard. Deseo, violencia, religión y libertad. Granada, Ed. Universidad de Granada, 2013. [http://hdl. handle.net/10481/26378] 
mimético ${ }^{1}$. René Girard se ha definido a sí mismo como un investigador que estudia de qué están hechas las relaciones humanas, renunciando a encasillarse en una disciplina o un enfoque particular. Si buscamos en Girard no sólo una respuesta, sino una elaboración teórica acerca de la definición de lo humano, no hallaremos ninguna obra sistemática al respecto. Sin embargo, encontraremos distintas obras, por no decir todas, que abordan esta cuestión de un modo u otro. Por tanto, ofreceremos aquí el resultado de un ejercicio de síntesis, ese que a veces echamos en falta en no pocas publicaciones del autor, que son largas entrevistas no muy sistemáticas.

\section{2. ¿Qué es la especie humana? Entre la diversidad disciplinar y la unidad del principio mimético}

Girard, recuperando la aspiración original de la ciencia antropológica y, a contrapelo de los que parecen ser los intereses mayoritarios de la investigación etnológica actual, se enfrenta a la resolución de dos cuestiones, que son, en el fondo, dos caras de la misma moneda, en tanto que apuntan a un nivel fundamental o primordial de lo humano: ¿cuál es el origen de la especie humana? y, más allá de toda diferencia, ¿cuáles son los ejes vertebradores de todas las culturas humanas? Esta empresa tiene un marcado carácter renacentista e ilustrado en tanto que supone la unidad del género humano y del conocimiento, y la interrelación de saberes. Además, supone la confianza en la capacidad del discurso científico y del lenguaje para acceder al conocimiento de lo real, frente a los discursos filosóficos relativistas, escépticos y nihilistas.

El pensador pretende aunar las intuiciones acertadas tanto de la etología y su enfoque biológico, como de la etnología culturalista, desechando los errores de ambas ${ }^{2}$. Girard parte del mimetismo y del mecanismo del chivo expiatorio (posibilitado por el mimetismo). Inspirado por algunas de las grandes obras literarias de todos los tiempos (de los relatos del Antiguo Testamento a Shakespeare), pretende, franqueando las fronteras disciplinares (historia, antropología, crítica literaria, mitología, biología...), aclarar las vicisitudes de las relaciones entre los seres humanos y de su origen y desarrollo como especie. Según el propio Girard fueron los grandes novelistas quienes le revelaron el carácter mimético del deseo y la rivalidad, como argumenta en su primera obra Mentira romántica y verdad novelesca. La curiosidad por saber si este deseo era universal -y su preocupación por la cuestión de los sacrificios-, le llevó a leer a los clásicos de la etnología que se lo confirmaron. De este modo, once años después, en 1972, aparece La violencia y lo sagrado con la formulación de sus tesis acerca de la violencia y el asesinato colectivo.

1 El ciclo o «mecanismo mimético» se refiere a toda la serie de fenómenos que abarcan desde el deseo mimético al desarrollo y conclusión de los crímenes victimarios. El ciclo mimético «comienza con el deseo y las rivalidades, continúa con la multiplicación de escándalos y la crisis mimética y concluye con un mecanismo victimario». R. Girard: Veo a Satán caer como el relámpago, Barcelona, Anagrama, 2002, p. 60; Los orígenes de la cultura, Madrid, Trotta, 2006, p. 51.

2 Camille Tarot denomina este modo de proceder como una manera «típicamente pascaliana» de construir el debate con y entre sus adversarios: «se toman dos familias de pensamiento que se combaten, se muestra lo que cada una dice mejor, pero también lo que le falta ver y que es en general simétrico e inverso, y se propone una tercera vía (más) completa. [...] El procedimiento es retomado varias veces por Girard cuando confronta para superarlos a Frazer y Lévi-Strauss, el occidentalismo y el primitivismo, el evolucionismo y el multiculturalismo, pero también Tarde y Durkheim [...] e incluso la crítica literaria y las ciencias humanas o la filosofía y las ciencias». C. Tarot: Le symbolique et le sacré. Théories de la religion, Paris, La Découverte, 2008, pp. 651-652. 
Girard rechaza la especificidad demasiado absoluta que se ha conferido al deseo humano. Habría que hablar, más bien, de una especificidad relativa puesto que ya en los animales las interferencias miméticas se injertarían sobre los apetitos y las necesidades, aunque nunca en el mismo grado que en los hombres: «El deseo forma parte ciertamente de estos fenómenos propiamente humanos que sólo pueden aparecer más allá de un cierto umbral mimético», lo cual no quiere decir que pasar ese umbral de hominización coincida con la aparición de un deseo comparable al que podamos experimentar actualmente ${ }^{3}$. Rechaza partir de las prohibiciones del incesto o de motivos económicos o sociopolíticos. Los puntos de vista freudiano o marxista le parecen inferiores, ya que no plantearían realmente el problema de la hominización sobre el fondo de la animalidad, que es de lo que habría que dar cuenta. Comenzar por el mimetismo le permite mostrar, en cambio, no sólo lo que tendríamos en común con los animales, sino la ruptura que, con respecto a ellos, tendría lugar con los primeros grupos humanos ${ }^{4}$. Afirmar científicamente la existencia del mecanismo del chivo expiatorio en los umbrales de la hominización, es una empresa quizás imposible por los cientos de miles de años transcurridos, y cabría discutir al respecto si los indicios y argumentos de Girard son más o menos sólidos y coherentes. Sin embargo, la imitación es reconocida científicamente como un proceso psicológico básico de los seres humanos ${ }^{5}$, lo que da pie a atribuirle un importante papel en las teorías filogenéticas.

\section{La propuesta de la teoría mimética: más allá de la etología y la etnología}

Si hay algo fuera de toda duda para Girard es el carácter mimético de los seres humanos y el inmenso e insospechado papel que el mimetismo juega en la cultura humana ${ }^{6}$. Esto, lejos de conservar la secular ruptura metafísica entre animales y hombres, viene a suscribir la inscripción de nuestra especie en el orden evolutivo. La diferencia estribaría en que el ser humano sería, como dijo Aristóteles, el animal imitador por excelencia ${ }^{7}$.

Girard edifica una teoría completa de la cultura humana a partir del único principio de la mímesis de apropiación. Cree que debe ser posible pensar el proceso de hominización de forma radical, partiendo de la animalidad sin caer en falsas especificidades de la naturaleza humana. En los primates más cercanos al hombre el cerebro es ya relativamente más voluminoso que en los otros animales. Girard piensa que esta capacidad creciente debe haber desencadenado el proceso de hominización y no a la inversa (incluso aunque este mismo proceso haya acelerado y contribuido a la incomparable capacidad cerebral humana) ${ }^{8}$. La neotenia del

3 R. Girard: El misterio de nuestro mundo, Salamanca, Sígueme, 1982, pp. 321-322.

4 Ch. Ramond: Le vocabulaire de René Girard, Paris, Ellipses, 2009, p. 46.

5 J. L. Martorell; J. L. Prieto: Fundamentos de psicología, Madrid, Ramón Areces, 2010, p. 7.

6 R. Girard: Veo a Satán..., loc. cit., p. 83.

7 Aunque no toda imitación implica el deseo, «cualquier mimesis referida al deseo desemboca automáticamente en el conflicto». R. Girard: La violencia y lo sagrado, Barcelona, Anagrama, 1983, p. 153. Girard se muestra en ocasiones menos radical: «El deseo mimético no siempre es conflictivo, pero suele serlo». R. Girard: Veo a Satán..., loc. cit., p. 26. El autor francés no encuentra en la historia de la filosofía ningún planteamiento que, a su juicio, asuma el mimetismo y su carácter conflictivo como lo que define al hombre (R. Girard: Clausewitz en los extremos, Buenos Aires, Katz, 2010, p. 155). Sin embargo, para St. Vinolo, el autor realiza un juicio abusivo cuando afirma que Platón no ve las consecuencias sociales de la mímeis y cree que habría otros pensadores que habrían podido afrontar el problema de la violencia mimética (Hobbes, Rousseau, Spinoza, Kierkegaard). St. Vinolo: René Girard: du mimétisme à l'hominisation, Paris, L'Harmattan, 2005, p. 72.

8 R. Girard: El misterio..., loc. cit., p. 108. 
niño humano y el largo periodo de crianza de éste es un factor de vulnerabilidad mayor que en la progenie del resto de mamíferos. Pero, al mismo tiempo, junto con el crecimiento posnatal del cerebro -el más considerable de los primates y por el cual la osamenta del cráneo no se cierra hasta bien después del nacimiento- tiene que ver con las extraordinarias capacidad y flexibilidad del cerebro humano, posibilitando los aprendizajes culturales ${ }^{9}$.

La mímesis tiene un papel relevante en los mamíferos superiores y aún más en los monos antropoides, nuestros parientes más cercanos, en los que se manifiesta la propensión a la imitación a veces en forma de «humor querelloso, peleón». Según los etólogos las relaciones de subordinación (redes, esquemas o patrones de dominio o dominancia, o dominance patterns), tienen un papel decisivo en las formas de sociabilidad animales ante los conflictos y las rivalidades animales que tienen que ver con la disputa de objetos, aunque pueden ir más allá ${ }^{10}$. El primer individuo que cede lo hará a partir de ahora y, sin combate, dejará al vencedor los mejores trozos de alimento y las hembras de su elección. Aunque esta situación no tiene por qué no verse alterada, estos patrones generan la cierta estabilidad que permite las sociedades animales ${ }^{11}$. Sin embargo, mientras que los animales contienen su violencia gracias a los dominance patterns, los hombres no serían capaces de contener sus conflictos de reciprocidad violenta ${ }^{12}$.

En el conflicto entre etólogos y etnólogos, Girard da la razón a los primeros, que protestan por la «insularidad» extraordinaria de la etnología culturalista y estructuralista, al oponerse a situar a la cultura humana en la naturaleza ${ }^{13}$. Y también a los segundos, que critican a los etólogos en tanto que proyectan el sistema de las sociedades humanas en su representación de las sociedades animales y negarían las peculiaridades humanas ${ }^{14}$. El pensador cree que su antropología basada en el mecanismo del sacrificio victimario es pionera en abandonar el postulado metafísico de la absoluta especificidad de lo humano, del que seguirían presos a su juicio Marx y Freud, al mismo tiempo que tampoco caería en el simplismo de asimilar al hombre y al animal como en el caso de los etólogos ${ }^{15}$. Los hombres, dada su especial capacidad mimética, estarían en una mayor exposición a un contagio violento que acabaría frecuentemente en ciclos de venganza y violencias en cadena: «el verdadero secreto del conflicto y de la violencia es la imitación deseante, el deseo mimético y las rivalidades feroces que engendra ${ }^{16} \cdot$ ¿Qué sucede en el deseo humano ${ }^{17}$ para que esto sea así? Según la teoría mimética el deseo humano no se enraíza ni en los objetos deseados ni en el sujeto deseante, sino en un tercero, el modelo o mediador de nuestros deseos. Podríamos pensar que la virulencia de los conflictos humanos podría deberse a la sexualidad humana y a su carácter permanente, no ceñido a ningún periodo como en los animales ${ }^{18}$. Sin

9 Ibídem, pp. 97-98.

10 R. Harré y R. Lamb (dir.): Diccionario de etología y aprendizaje animal, Barcelona, Paidós, 1991, pp. 60-62.

11 R. Girard: El misterio..., pp. 103-104. René Girard: Sanglantes origines, Flammarion, 2011, p. 81.

12 R. Girard: Clausewitz..., loc. cit., p. 47.

13 A Girard le parece mérito de la etología haber señalado las indudables semejanzas entre socialidad animal y humana y se apoya en E. Morin para afirmarlo. R. Girard: El misterio..., loc. cit., pp. 105, 97.

14 Ibídem, pp. 105-106.

15 R. Girard: Literatura, mímesis y antropología, Barcelona, Gedisa, 1997, p. 207.

16 R. Girard: Aquel por el que llega el escándalo, Madrid, Caparrós, 2006, p. 21.

17 Al hablar de «deseo humano» no presuponemos que lo haya de otro tipo, sino que enfatizamos que nos referimos al hombre. No obstante en la teoría mimética girardiana no hay una exposición nítida en lo que a la distancia entre interferencia mimética (animal o humana) y deseo mimético (humano) se refiere.

18 R. Girard: Aquel por el que llega..., loc. cit., p. 130. 
embargo, aunque las rivalidades miméticas pueden ser sexuales, frente a lo que los freudianos pudieran hacer creer, las rivalidades abarcarían todas las esferas de lo humano ${ }^{19}$.

Girard rechaza los que considera los dos grandes enfoques modernos de la violencia por resultarle estériles. El político y filosófico optimista antropológico, que toma al hombre como bueno por naturaleza y que estaría corrompido por la sociedad. Y el biológico, según el cual la especie humana es la sola capaz de ejercer la violencia, en contraste con una supuesta apacible vida animal. Si Freud hablaba de un instinto de muerte y otros buscan hoy los genes de la agresividad humana, Girard propone la hipótesis mimética distinguiendo el deseo humano, de los apetitos y necesidades biológicas compartidos por hombres y animales, y que siempre serían los mismos. La imitación es importante en los mamíferos superiores, sobre todo en los grandes simios, que nos son más cercanos, pero lo sería aún más en los hombres. Así, lo que nos hace más inteligentes y dinámicos y «sobrepasar» a los animales sería, a la vez, lo que nos hace más violentos, combativos y tener menos equilibrio que ellos ${ }^{20}$.

El ser humano sería fundamentalmente competitivo porque los hombres desearían siempre las mismas cosas que los otros hombres. Según el autor, al ser «miméticos» se entregan a guerras intestinas, a conflictos sin fin, instaurando «círculos viciosos de violencia» de los que no se podría salir (salvo, como veremos, por la acción del mecanismo sacrificial) ${ }^{21}$. Así, otra gran posible fuente de conflictos como puede ser la escasez de bienes, se vería sobrepasada permanentemente por el hecho de que siempre querríamos tener lo que quiere el otro ${ }^{22}$. Lo que definiría el conflicto humano no sería el que haya una pérdida de reciprocidad sino su desplazamiento, cada vez más rápido, de la buena a la mala reciprocidad. Las relaciones humanas consistirían en una doble imitación perpetua recíproca, tanto si se trata de una relación benevolente y pacífica, como si lo es maliciosa y belicosa ${ }^{23}$. Girard prefiere detenerse en las relaciones más concretas, olvidadas por los científicos sociales y que serían la base de la discordia, de tal forma que los individuos entran en conflicto «porque en sus relaciones en este momento intervienen determinados mecanismos que son típicos de las relaciones directas y locales» ${ }^{24}$.

Las rivalidades miméticas en los hombres desembocarían fácilmente en la locura y el crimen. Más allá de un cierto nivel de fuerza mimética, las sociedades animales devendrían imposibles: «este umbral corresponde entonces al umbral de la aparición del mecanismo victimario; es el umbral de la hominización» ${ }^{25}$. De esta forma, ceder a la violencia sería el comienzo de lo humano ${ }^{26}$ y «lo único que puede detener a la violencia general es la propia violencia» ${ }^{27}$ (cuando la violencia de todos contra todos se vaya concentrando en una persona o en un grupo).

El control de la violencia constituye un problema y las guerras primitivas habrían transcurrido entre grupos vecinos de hombres sin apenas distinción entre sí. Sin diferencias entre el enemigo externo y el amigo interno, ¿cómo podrían los mecanismos instintivos dar cuenta

19 R. Girard : «Les appartenances », en : D. Mazzú (dir.) Politiques de Cä̈n, Desclée, 2004, pp. 23-25.

20 R. Girard: Aquel por el que llega..., loc. cit., p. 15-17.

21 R. Girard (et G. Vattimo): Christianisme et modernité, Paris, Flammarion, 2009, pp. 28-29.

22 G. Groot: «Emociones de segunda mano. Conversación con René Girard», en: Adelante, jcontradígame! Filosofía en conversación, Madrid, Sequitur, 2008, p. 61.

23 R. Girard: Aquel por el que llega..., loc. cit., pp. 23-24.

24 G. Groot: «Emociones...», loc. cit., pp. 62-63.

25 R. Girard: El misterio..., loc. cit., p. 109.

26 R. Girard: Aquel por el que llega..., loc. cit., pp. 97.

27 G. Groot: «Emociones...», loc. cit., p. 61. 
de la diferencia en el comportamiento? De hecho, en tanto que no instintiva, esta diferencia puede abolirse y dar lugar a crímenes intrafamiliares. Girard constata, como han hecho otros investigadores, la importancia evolutiva del dominio de la rabia que, lejos de ser naturalmente centrífuga, una vez que se exaspera es centrípeta y tiende a orientarse hacia los seres más cercanos y queridos, protegidos normalmente por la regla de no violencia. Aunque esos investigadores se hacen cargo de ello no explicarían, sin embargo, por qué y cómo ha sido controlada la rabia ${ }^{28}$. Invocar este dominio de la rabia, decir que la «cultura» ha resuelto los problemas, o que todo es cuestión de «evolución» no resuelve nada. Es la misma crítica que hace Girard a Hubert y a Mauss que apuntarían al sacrificio como el origen de todo lo religioso, pero sin decir nada acerca del origen mismo del sacrificio ${ }^{29}$.

Habría que imaginar cómo algunos primeros y pequeños grupos de hombres, incapaces de contener las escaladas miméticas de reciprocidad violenta en su comunidad, cada vez más rápidas e intensas, habrían sucumbido a la lucha de todos contra todos autodestruyéndose ${ }^{30}$. La cultura humana se revelaría así, principalmente, como «un esfuerzo para impedir que la violencia se desencadene separando y «diferenciando» todos los aspectos de la vida pública y privada que, si son abandonados a su reciprocidad natural, amenazan con hundirse en una violencia irremediable» ${ }^{31}$. Una vez que se ha perdido parte del instinto animal a cambio de un deseo móvil y no prefijado ${ }^{32}$, ¿de qué forma se concretarían estos primeros esfuerzos culturales humanos para no sucumbir a una crisis de violencia incontrolada? ¿Cómo se intentaría resolver el problema número uno de toda comunidad humana, la violencia interna? ${ }^{33}$. Veamos cómo el autor intenta responder a estas cuestiones con la hipótesis del chivo expiatorio, que considera una hipótesis científica ${ }^{34}$, no sin antes presentar un breve resumen de esta.

\section{Breve descripción del mecanismo del chivo expiatorio}

No es baladí detenerse aquí, ya que no son pocas las confusiones que se dan, incluso en debates ya publicados en torno a este mecanismo ${ }^{35}$. El autor distingue tres usos distintos de

28 R. Girard: El misterio,..., loc. cit., pp. 101-102. Svante Pääbo, del Instituto Max Planck de Antropología evolutiva, también considera fundamental la progresiva autodomesticación humana en el dominio de la violencia y la agresividad, y apunta a un proceso de selección genética y cultural en el que irían prevaleciendo los individuos con mayor docilidad y sociabilidad, facilitando la adaptación de la especie humana para la convivencia en sociedad. Nos remitimos a la entrevista que E. Punset hace a Svante Pääbo en el programa «Redes» de Televisión española: «Rastrear el pasado por medio de la genética» [emisión original: 2/10/11; última consulta: 15/5/13]; <http://www.rtve.es/alacarta/videos/redes/redes-rastrear-pasado-medio-genetica/1212707/>. El papel de los ritos y prohibiciones religiosas en esta autodomesticación humana no sería incompatible con esta consideración y probablemente ambas hipótesis podrían reforzarse entre sí.

29 R. Girard: La violencia y lo sagrado, Barcelona, Anagrama, 1983, p. 97.

30 R. Girard: Achever..., loc. cit. p. 47.

31 R. Girard: Aquel por el que llega..., loc. cit., p. 25.

32 R. Girard: Veo a Satán..., loc. cit., p. 34.

33 Ibídem, p. 25.

34 Sobre la defensa del carácter científico de su hipótesis puede verse: La violencia y lo sagrado, loc. cit., p. 322 y ss., además de: Literatura, mímesis..., loc. cit., pp. 14-15; 219-220. Sobre la crítica a la no falsabilidad de la teoría: R. Girard: Aquel por el que llega..., loc. cit., pp. 116-117. Véase también: A. Moreno Fernández: La evaluación de la modernidad en la teoría mimética..., loc. cit., p. 414 y ss.

35 L. Scubla, «Avant-Propos», en: R. Girard (et al.): Sanglantes origines, loc. cit., p. V. A pesar de que el mecanismo del chivo expiatorio es un elemento básico en Girard, no encontramos en su obra una delimitación clara 
esta noción ${ }^{36}$, pero la definición que privilegia, sobre todo en lo que concierne a las sociedades primitivas, es la de un mecanismo espontáneo que se desencadena con ocasión de una crisis mimética (caracterizada por la rivalidad, el caos y la violencia) y que consiste en un proceso colectivo e inconsciente de «acusación», linchamiento y sacralización de una víctima inocente, que canaliza la violencia y pone fin a la crisis ${ }^{37}$. Si bien la gran capacidad mimética y cerebral humana hace posible el aprendizaje cultural, al mismo tiempo esto supondría un riesgo para la supervivencia. Como decimos, la inoperatividad de los dominante patterns en las primeras comunidades humanas, puede llevar hasta su autodestrucción. Lo humano comenzaría, pues, con la violencia irresoluble y con la que sería su solución, el mecanismo del chivo expiatorio.

Una crisis social se caracteriza por relaciones de imitación y reciprocidad intersubjetivas, conflictivas y de rivalidad, hasta que la violencia, la locura, las alucinaciones y la venganza interminable podrían llegar a un punto paroxístico en el que los flujos miméticos cambiarían de sentido. El caos total y la indiferenciación comenzarían a ordenarse gracias a la «mímesis antagonista». Es decir, poco a poco, los individuos se irían agrupando en la medida en que imitan el odio de otro hacia un enemigo común. Progresivamente el acuerdo se iría generalizando hasta que el odio se focaliza en un solo individuo (o en más). A continuación, el linchamiento unánime acaba con su vida. La comunidad se beneficia del efecto catártico de liberación de su odio y su violencia y vuelve la estabilidad. Serían muchas las ocasiones y los años en cuyo transcurso podría haberse desencadenado este mecanismo sin suscitar reflexión alguna. Hasta que, en un determinado momento, el cadáver de la víctima daría pie a la comunidad a pensar qué ha sucedido. Y aquí comenzaría la sacralización ambivalente de la víctima, considerada culpable de los males que acechaban al grupo. En las sociedades primitivas no se distingue entre causas internas y externas del malestar en el seno de una comunidad. Así que no importa que fuese una disputa por el liderazgo, una hambruna, una sequía o una tempestad el motivo de la crisis para desencadenar las luchas intracomunitarias o para achacar la culpabilidad a uno o a varios de sus miembros.

Se le atribuye a la víctima un gran poder, capaz de haber traído el mal y la violencia, un poder sobrenatural maléfico. A la vez, se le adjudica la responsabilidad del advenimiento de la paz al seno de la comunidad, acaecido tras su muerte. Por tanto, también se le confiere una influencia benéfica. Esta sería la misma ambivalencia constituyente de lo sagrado. El hombre, afirma Girard, es el animal asesino que sacraliza a sus víctimas. Éste es el precio de su humanización y de la supervivencia comunitaria. Se aplaca una violen-

de cada una de sus fases. Tampoco lo hacen, por citar algunos casos: A. Llano (Deseo, violencia, sacrificio, Barañáin, Eunsa, 2004); P. Ruiz (Antropología y religión en René Girard, Granada, Facultad de Teología de Granada, 2005); St. Vinolo (René Girard: du mimétisme à l’hominisation, loc. cit.; René Girard: Épistémologie du sacré, L’Harmattan, Paris, 2007) o E. Haeussler (Des figures de la violence, Paris, L’Harmattan, 2005), aunque, por supuesto, sí encontremos una descripción del proceso más o menos profunda. En nuestro caso hemos propuesto una descripción agrupada en seis fases, que no se identifican con un solo momento o fenómeno. A. Moreno Fernández: La evaluación de la modernidad en la teoría mimética ..., loc. cit., pp. 35-57.

36 Estos son: el ritual descrito en el Levítico con el macho cabrío para expiar los pecados; las víctimas de rituales análogos en otras sociedades y los fenómenos de transferencia de culpabilidad que podemos observar hoy a nuestro alrededor. R. Girard: Veo a Satán..., loc. cit., p. 206.

37 Para una exposición detallada de los distintos matices de esta noción: Ch. Ramond: Le vocabulaire de René Girard, Paris, Ellipses, 2005, pp. 5-9. Girard marca distancias con Freud y aclara que «aparte de la tesis del asesinato colectivo que considero genial, el mayor descubrimiento de toda la etnología antigua, no he admirado nunca nada en Totem y tabú». R. Girard: Aquel por el que llega..., loc. cit., pp. 112-113. 
cia mayor e incontrolada a costa de una menor, la cual aunque en origen es espontánea, será cuidadosamente ritualizada a lo largo del tiempo.

Cuando lleguen nuevas crisis la comunidad recordará cómo se salió de la anterior o de la supuestamente primigenia, que es la que va a evocarse. Y si no hay una crisis ésta puede llegar a provocarse o simularse, buscando seguir las fases del mecanismo. Éste sería el sentido de la presencia de drogas y alucinógenos en muchos ritos que anteceden a los sacrificios o de las danzas con máscaras, asociadas a la indiferenciación caótica social. De este modo, la religión nacería como el intento de la humanidad por encontrar respuestas e instrumentos ante su amenaza más temida y mortífera: la violencia interna y disgregadora que puede aniquilar al grupo. Los mitos serían los relatos tergiversados de la realidad por la comunidad, el punto de vista de los verdugos, que intentan narrar lo sucedido y que, sin saberlo, justifican la culpabilidad de la víctima, eludiendo la responsabilidad común en los conflictos sociales y en el mecanismo emisario $^{38}$. Los ritos de cada cultura serían la rememoración reglada de sus crímenes fundadores. Las sociedades humanas serían producto de procesos miméticos disciplinados por el rito e hijas de lo religioso. Las versiones de los mitos y ritos que nos son accesibles representarían, de una manera más o menos velada, el proceso de chivo expiatorio y de la violencia fundadora, concebidos como el origen de la cultura. Pueden verse así distintas evocaciones de diferentes fases de este mecanismo, en una infinidad de variantes incrementadas por la ambivalencia de lo sagrado y las elaboraciones de cada cultura a lo largo de los siglos.

\section{El mecanismo victimario, clave del proceso de humanización}

Girard ve en el mecanismo victimario y en su funcionamiento mimético el motor necesario para explicar la interacción de lo biológico y de lo cultural que exigía el rápido aumento del cerebro. A partir de aquí concibe la humanización como una serie de «rellanos» que permitirían domesticar las siempre crecientes intensidades miméticas, separadas por nuevas crisis que vuelven a desencadenar el mecanismo y, a su vez, nuevas prohibiciones y rituales, cada vez más eficaces. De esta forma, gracias a la sucesión de crisis, sacrificios y elaboraciones rituales el antropoide se habría ido humanizando cada vez más ${ }^{39}$. Está de acuerdo en incorporar la religión al ámbito de la técnica, considerando la técnica del chivo expiatorio la madre y la más antigua de todas las técnicas ${ }^{40}$.

Frente a las teorías del contrato social Girard observa que «sólo los universitarios y burócratas se imaginan que todo comienza siempre por comités» ${ }^{41}$ e inscribe la génesis de la cultura humana en la naturaleza, vinculándola a un mecanismo natural sin quitarle lo que tiene de exclusivamente humano. Quiere resolver así la querella entre etólogos y etnólogos, mostrando que hay siempre, y a la vez, ruptura y continuidad entre todas las formas sociales, animales primero, pre-humanas a continuación, y completamente humanas finalmente ${ }^{42}$.

38 Por ejemplo, los mitos de los dioses del Olimpo serían los trazos de crímenes de las comunidades contra sus víctimas, chivos expiatorios divinizados acusados previamente de parricidios, incestos, fornicaciones bestiales y otros crímenes, todos ellos acusaciones típicas de caza de brujas que obsesionan a las multitudes arcaicas e incluso modernas que buscan víctimas. Ch. Ramond: Le vocabulaire..., loc. cit., p. 59.

39 R. Girard: El misterio..., loc. cit., pp. 109-110.

40 R. Girard: El chivo expiatorio, Barcelona, Anagrama, 1986, p.135.

41 R. Girard: Cuando empiecen a suceder estas cosas, Madrid, Encuentro, 1996, p. 38.

42 R. Girard: El misterio..., loc. cit., pp. 110-111. 
Obviamente no es posible remontarse hasta estos fenómenos y encontramos un enorme agujero, quizás de millones de años ${ }^{43}$. Sin embargo, esta tentativa no sería arbitraria, al apoyarse en una ingente cantidad de indicios convergentes de los ritos humanos que coinciden con los «ritos animales» observados en etología ${ }^{44}$. Investigaciones como la de K. Lorenz sugieren que la violencia humana no es la única en dotarse de objetos de recambio ${ }^{45}$. Es más, hay conductas animales en ciertas especies que evocarían los dos momentos fundamentales de los ritos religiosos: el de la crisis mimética y el de la reconciliación contra la víctima emisaria. No obstante, una diferencia esencial entre humanos y animales sería que en el caso de los ritos de éstos nunca hay un número suficiente de miembros para asemejarse a los ritos fundamentales de la humanidad, que reúnen a un grupo social por entero ${ }^{46}$.

Se intenta mostrar, en definitiva, que la persecución unánime debe jugar en la génesis de la cultura humana, en el umbral de la hominización, el rol que desempeñaban los esquemas de dominio $^{47}$. El pensamiento simbólico, el conjunto del lenguaje humano y las demás instituciones culturales tendrían también su origen en los homicidios colectivos ${ }^{48}$. Tras cada crimen y su paroxismo histérico, se produciría el advenimiento de la calma y, por tanto, las condiciones favorables al pensamiento: «los hombres se dirigen hacia el milagro a fin de perpetuarlo y renovarlo; necesitan por consiguiente, en cierto modo, pensarlo. Los mitos, los rituales, los sistemas de parentesco, constituyen los primeros resultados de este pensamiento. Quien formula el origen del pensamiento simbólico formula al mismo tiempo el origen del lenguaje» ${ }^{49}$.

Girard considera que el primer ejercicio de atención no instintivo debió haber tenido lugar, ante una víctima ejecutada, en el contraste entre el estrépito y el silencio acaecidos antes y después del linchamiento. El cadáver de la víctima colectiva ante la mirada de todos sería el primer símbolo, el primer objeto de este nuevo tipo de atención (y no un objeto sexual, alimentario o instintivo). Aunque no hubiese aún conceptos ni representaciones, sí cabría una «conciencia» vinculada a la experiencia sobrecogedora de la crisis y su resolución y a la ambivalencia de los efectos prodigiosos atribuidos a la víctima: «basta admitir que estos efectos son tan débilmente acumulativos como se quiera para afirmar que ya se está en camino hacia las formas humanas de la cultura» y hacia lo sagrado ${ }^{50}$. Girard propone un modelo más simple que el de la oposición binaria de la lingüística estructural para su teoría del signo. Se trata del modelo de echar a suertes, de la paja más corta o más larga, o del trozo de roscón de reyes que tiene el haba. Sólo estos elementos son significativos y los demás quedan indeterminados. Sería el sistema simbólico más simple, el modelo de la excepción en curso de emergencia, «de la unidad única capaz de emerger de una masa confusa, de una multiplicidad todavía innominada» ${ }^{51}$.

43 R. Girard: Aquel por el que llega..., loc. cit., p. 93.

44 R. Girard: El misterio..., loc. cit., p. 111-112.

45 Como en el caso estudiado por Lorenz de cierto pez que, privado de sus congéneres machos, sus adversarios habituales, dirige sus tendencias agresivas contra su propia familia a la que acaba por destruir. R. Girard: La violencia ..., loc. cit., pp 10-11. O la descripción de Lorenz del comportamiento de las ocas. R. Girard: Los orígenes..., loc. cit., p. 116.

46 R. Girard: El misterio..., loc. cit., pp. 111-112.

47 R. Girard: Sanglantes origines, loc. cit., p. 89.

48 R. Girard: El chivo expiatorio, loc. cit., p. 251.

49 Esta génesis del pensamiento simbólico es lo que intenta mostrar Girard en La violencia y lo sagrado al analizar el mito de Edipo y el de Dionisos. R. Girard: La violencia y lo sagrado, loc. cit., p. 242.

50 R. Girard: El misterio..., loc. cit., pp. 113-114 ; Sanglantes origines, loc. cit., pp. 89-90.

51 R. Girard: El misterio..., loc. cit., p. 114. 
La selección por azar alude a los ritos y, a veces, también sirve para elegir a las víctimas de los sacrificios. Sería el modelo de simbolicidad más rudimentario. Es también gracias a la víctima, que parece salir de la comunidad y de la cual parece salir la comunidad, que pueda darse lugar a pensar «un dentro y un afuera, un antes y un después, una comunidad y un algo sagrado. [...] Esta víctima se presenta a la vez como mala y como buena, como pacífica y como violenta, como vida que hace morir y como muerte que asegura la vida. No hay ninguna significación que no se esboce en ella y que no parezca al mismo tiempo trascendida por ella. Da la impresión de que se constituye entonces como significante universal» ${ }^{52}$.

El pensador apostilla que «no hay cultura en el mundo que no afirme como primeros y fundamentales en el orden del lenguaje los vocablos de lo sagrado ${ }^{53}$, convencido de que puede mostrarse «que no hay nada en la cultura humana que no pueda reducirse al mecanismo de la víctima expiatoria» ${ }^{54}$. Teniendo en cuenta lo dicho puede comprenderse la tesis girardiana según la cual no sólo, como en el caso de Durkheim, «lo social y lo religioso son la misma cosa ${ }^{55}$, sino que, más allá, «la humanidad es hija de lo religioso» ${ }^{56}$; «no existiría sin lo religioso» ${ }^{57}$. Las sociedades humanas habrían surgido de lo religioso arcaico por medio de los crímenes fundadores, serían producto de procesos miméticos disciplinados por los ritos derivados de aquellos asesinatos ${ }^{58}$. Sería gracias a la protección contra la violencia interna de las comunidades, procurada por sus víctimas propiciatorias, por lo que se habrían llevado a cabo las empresas humanas ${ }^{59}$. Dicho de otro modo, las religiones de la violencia habrían sido medios que han servido al principio a la humanidad para salir de la animalidad y elevarse hacia posibilidades inauditas ${ }^{60}$; o aún con otras palabras: la historia de las religiones sería la de una muy lenta «autodomesticación» del hombre, de lentos tanteos para edificar sociedades lo bastante estables como para perdurar en la historia ${ }^{61}$. Los sacrificios se repetirán durante centenares de miles de años hasta llegar a la domesticación animal, los reyes sagrados y las instituciones (los hindúes tendrían razón al explicarlas remitiéndose al sacrificio). Y esto sería el resultado de «una especie de selección natural» ${ }^{62}$.

Para el autor francés, que el grupo decide siempre por el individuo, sería una evidencia social que es la ley de lo religioso y que la modernidad individualista no habría querido ver. Sí la habría visto Durkheim de quien Girard dice haber retomado su tesis, añadiendo la imitación como motor de la construcción social, como Gabriel Tarde. En cambio, Girard dice ser más radical que Tarde, a quien reprocha no haber descubierto nunca la mímesis violenta, presente en la raíz de todas las instituciones, fundadas sobre el mecanismo del chivo expiatorio. En su opinión, las instituciones nacen gracias a la repetición de los ritos, (evocación del sacrificio primero con víctimas de sustitución: niños, animales, ofrendas...) que son ejecutados al amparo de los mitos (el relato tergiversado, sin conciencia de ello, del linchamiento fundador). De esta

52 Ibídem, p. 816.

53 Ibídem, p. 118.

54 Ibídem, p. 61.

55 R. Girard (et. al.): Dieu, une invention?, Paris, Editions de L'Atelier, 2007, p. 56.

56 R. Girard: Veo a Satán..., loc. cit., p. 128.

57 R. Girard : Dieu..., loc. cit., p. 56.

58 R. Girard: Veo a Satán..., loc. cit., pp. 127-128.

59 R. Girard: La violencia y lo sagrado, loc. cit., pp. 243-244.

60 R. Girard: El misterio..., loc. cit., p. 441.

61 L. Scubla : «Avant-propos », en: R. Girard : Sanglantes origines, loc. cit., p. III.

62 R. Girard: Aquel por el que llega..., loc. cit., pp. 92, 94-95. 
manera «la mímesis apacible es posibilitada únicamente dentro del marco de una institución ya afianzada, fundada largo tiempo atrás: tiene por bases el aprendizaje y la preservación de los códigos culturales» ${ }^{63}$. La religión y, en particular, las dos grandes instituciones de la religión arcaica, las prohibiciones y el sacrificio, determinarían el tránsito de las sociedades pre-humanas a las sociedades humanas impidiendo a los homínidos autodestruirse ${ }^{64}$. Por ello no resulta de extrañar a Girard que la idea según la cual los dioses son los que enseñan a los hombres los sacrificios que llevan a cabo, sea una idea universal ${ }^{65}$.

Esos dioses, como hemos visto, serían las víctimas del mecanismo sacrificial sacralizadas. Sería fácil concluir otro tanto con respecto a la figura de Jesús en el cristianismo. Sin embargo, según Girard, los textos del Evangelio serían los anti-mitos por excelencia, los que desenmascararían el relato tergiversado del crimen colectivo. Si la clave del éxito de la pacificación social de los crímenes colectivos es la creencia unánime en la culpabilidad de la víctima, en el relato evangélico encontramos la perspectiva de la víctima, de una minoría disidente que no cree que Jesús sea culpable, opuesta a la de los perseguidores. En particular, la Pasión revela para Girard la verdad antropológica de nuestra historia de animales culturales, que no han cesado de buscar chivos expiatorios para resolver con su sacrificio las crisis de violencias internas, divinizándolos sin saber lo que se hacía ${ }^{66}$. La divinización cristiana sería la sacralización de una víctima inocente y no de una supuesta víctima culpable, coartada de la violencia colectiva ejercida contra ella. Desde un punto de vista antropológico los Evangelios son definidos por Girard «como un mapa de carreteras de las crisis miméticas y su resolución mítico-ritual, una guía que permite circular por lo religioso arcaico sin extraviarse» ${ }^{67}$. Aunque el cristianismo, precedido por el judaísmo, sea considerado el punto culminante en el reconocimiento de las víctimas, Girard valora la existencia de un progreso civilizatorio, considerando aportaciones, entre otros, de los trágicos griegos o de algunos textos de la tradición hindú ${ }^{6}$.

El pensador también concede un papel al cristianismo en la evolución humana y en su «acabamiento». En su opinión debemos al cristianismo el que hoy en día sea incuestionable el valor y la atención otorgados a las víctimas de cualquier índole. Asevera que «el cristianismo representa para la evolución humana lo que la cultura ha representado para la selección natural (cuando el hombre ya no es más víctima del mecanismo ciego de selección darwinista, y comienza a liberarse de él) $»^{69}$.

63 R. Girard: Clausewitz..., loc. cit., p. 52.

64 Ibídem, pp. 123-124.

65 R. Girard: Veo a Satán..., loc. cit., p 112. La obra de Girard está cuajada de mitos y ritos de todas las culturas del mundo que, a pesar de su diversidad, apoyarían su hipótesis del chivo expiatorio como un universal cultural y que sólo su teoría vincularía entre sí. Ejemplos de ello serían el incesto ritual del rey africano, la antropofagia tupinamba o el sacrificio humano azteca. R. Girard: La violencia y lo sagrado, loc. cit., pp. 314-315.

66 R. Girard: Christianisme et modernité,pp. 31 y 146. La difusión de los Evangelios produciría la desaparición de las religiones arcaicas: «donde el cristianismo penetra, los sistemas mítico-rituales se extinguen». R. Girard: $E l$ chivo expiatorio, loc. cit., p. 199. Los Evangelios no permitirían suponer que la violencia pueda atribuirse a un origen divino, sino que señalarían que ésta se enraíza en la naturaleza mimética de las relaciones humanas». R. Girard: Christianisme et modernité, loc. cit., p. 129.

67 R. Girard: Veo a Satán..., loc. cit., p. 236.

68 A. Moreno Fernández: «La violencia en las religiones según la teoría mimética de Girard», en: C. Castilla (coord.): El diálogo interreligioso, Granada, Comares, 2011, pp. 57-86.

69 R. Girard: Los orígenes..., loc. cit., p. 19. En opinión de A. Boyer, Girard no puede asegurar que los primeros cristianos suponen históricamente la única alternativa a lo sagrado arcaico y sacrificial: «¿Puede asegurar tam- 


\section{Conclusión}

El origen de la constitución contradictoria de los seres humanos queda situado en la teoría mimética en el producto biológico y cultural en que consistiría el mecanismo del chivo expiatorio. La violencia que nos califica como «inhumanos», como peores que los animales, sería el origen de nuestra humanidad. El control de nuestra violencia y nuestra humanización, vendría dado por más violencia, organizada espontáneamente en torno al asesinato de víctimas que, gracias a la catarsis sobrevenida en cada crimen o sacrificio, habría dotado de estabilidad a las comunidades. El hombre aprendería a ser humano con los sacrificios. El mimetismo exacerbado que nos separa y libera del orden sometido de los animales, sería el que nos somete a la violencia incontrolada. Al mismo tiempo que nos dota de instrumentos para aplacarla, nos habría hecho más inteligentes y habría posibilitado la cultura y el lenguaje. Lo que nos hace más frágiles e inestables, es lo que nos hace más capaces. El origen de las culturas y de las instituciones, prohibiciones, normas y valores se hallaría en la víctima sagrada, cuya muerte es el precio que «se paga». Girard dibuja una concepción del ser humano que, lejos del optimismo de las Luces y de su visión de aquel como animal racional, está necesitado de unas muletas sacrificiales que, además, requieren para su efectivo funcionamiento de la ignorancia.

Respecto a la antropogénesis, podemos concluir que según el planteamiento girardiano el ser humano es el animal imitador por excelencia, tanto para ejercer una violencia que puede autodestruirle, como para producir la cultura (sacrificial) y los medios de adaptación que le permitan sobrevivir. Girard elimina la falla establecida por los etnólogos culturalistas entre seres humanos y especies animales y, al mismo tiempo, define la especificidad humana, banalizada por la etología. Sitúa a la humanidad en el contexto evolutivo natural. Sostiene que la religión es un universal cultural y la dota como tal de una explicación coherente, aunque reduccionista ${ }^{70}$, así como a la ambivalencia de lo sagrado. Interpreta de manera unitaria la gran diversidad de las manifestaciones religiosas de todas las culturas. Y valora la tradición judeocristiana como aquella que plenamente habría revelado el sentido de las religiones arcaicas, asumido y denunciado la violencia humana, e invitado a los hombres a renunciar a ella, cumpliendo así su papel evolutivo en la cultura, aunque no estaría exenta de contradicciones.

bién que los Evangelios son la única revelación y denuncia del mecanismo sacrificial? Sócrates, por ejemplo, ¿no se proclama inocente él mismo y no acusa a la multitud de no haber respetado las leyes? [...] Sócrates no acepta ser chivo expiatorio». "Débat Cornelius Castoriadis-René Girard”, en: P. Dumouchel, J.P. Dupuy (dir.): L'auto-organisation. De la physique au politique, Paris, Éditions du Seuil, 1983. En este sentido, ¿qué argüiría Girard, por ejemplo, ante los argumentos de Voltaire? Ambos podrían compartir que la ciencia se abre paso gracias al progreso moral. Pero lo que el primero atribuye al cristianismo, el segundo lo vincula a la facultad de la razón y a la tolerancia. Voltaire: Tratado de la tolerancia, Barcelona, Crítica, 2004, p. 71.

70 Girard parece no hacerse cargo de la enorme complejidad de la fenomenología del hecho religioso. Como ha subrayado Gómez Caffarena, quedaría aquí sin justificar por qué ser tan riguroso a la hora de ver el origen mismo de lo sagrado en la etimología del sacrum-facio: «Sagrado’ parece ser más complejo y abarcante. Se han llamado también «sacrificio» simples ofrendas que refuerzan la plegaria sin inmolación destructiva». J. Gómez Caffarena: El Enigma y el Misterio. Una filosofía de la religión, Madrid, Trotta, 2007, pp. 55-56. 